\section{Géneros}

Multidisciplinary Journal of Gender: Studies

\section{Hipatia Press \\ www.hipatiapress.com}

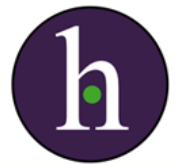

Instructions for authors, subscriptions and further details:

http://generos.hipatiapress.com

Salomé en el cine, un Weibermacht a la sombra de Wilde

Amelia Meléndez Táboas ${ }^{1}$

1) Unversidad Nebrija

Date of publication: October $25^{\text {th }}, 2019$

Edition period: October 2019- February 2020

To cite this article: Meléndez Táboas, A. (2019). Salomé en el cine, un Weibermacht a la sombra de Wilde. Multidisciplinary Journal of Gender Studies, 8(3), 281-304. doi: 10.17583/generos.2019.4579

To link this article: http://dx.doi.org/10.17583/generos.2019.4579

PLEASE SCROLL DOWN FOR ARTICLE

The terms and conditions of use are related to the Open Journal System and

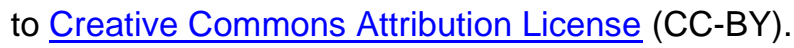




\section{Salome in cinema, a Weibermacht overshadow by Wilde}

Amelia Meléndez Táboas

Universidad Nebrija

\section{Abstract}

The Salome of Oscar Wilde became one of the fundamental ways of construction and access to a myth with nineteenth-century explanation and connotations and a perpetuated vigor in the cinema. The Salome of Oscar Wilde was an aesthetic vehicle of late Victorian gay emancipation as Ken Rusell knew how to denounce and explain. Access to the subject condition that was apparently achieved with the will to revenge was impaired by the instrumental interest of the author. Nevertheless, women artists saw in that wildeana drift of the myth a capital to resignify that it could be framed in a Weibermacht or genre of Power of Women. This operation of providing Salome with the status of a woman subject endowed with the power to act for her own benefit and that of her gender is paradoxically torpedoed by the vigor of Wilde's own text. But some titles that started from some later text or from the personal contribution of the director have opened up possibilities for that film Weibermacht of Salome. This is the case of Salome where she danced (Charles Lamont, 1945) whose analysis will use the methodology proposed by Sulbarán Piñeiro that combines semiotics and film narrative.

Keywords: Weibermacht, filmic, construction, imaginary, misogyny 


\title{
Salomé en el cine, un Weibermacht a la sombra de Wilde
}

Amelia Meléndez Táboas

Universidad Nebrija

\begin{abstract}
La Salomé de Oscar Wilde se convirtió en una de las vías fundamentales de construcción y acceso a un mito con explicación y connotaciones decimonónicas y un vigor perpetuado en el cine. La Salomé de Wilde fue un vehículo esteticista de emancipación homosexual tardo victoriana como Ken Rusell supo denunciar y explicitar. El acceso a la condición sujeto que en apariencia se conseguía con la voluntad de venganza se veía menoscabado por el interés instrumental del autor. No obstante, las mujeres artistas vieron en esa deriva wildeana del mito un capital a resignificar que cabría enmarcar en un Weibermacht o género de Poder de las Mujeres. Esa operación de dotar a Salomé de la condición sujeto mujer dotada de poder para obrar en su propio beneficio y el de su género se ve paradójicamente torpedeada por el vigor del propio texto de Wilde. Pero algunos títulos que partían de algún texto posterior o de la aportación personal del director han abierto posibilidades para esa Weibermacht fílmica de Salomé. Es el caso de Salome where she danced (Charles Lamont, 1945) para cuyo análisis se empleará la metodología propuesta por Sulbarán Piñeiro que aúna semiótica y narrativa fílmica.
\end{abstract}

Keywords: Weibermacht, fílmica, construcción, imaginario, misoginia 


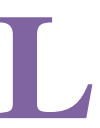

a construcción cultural del mito de Salomé partió de la Biblia, la literatura simbolista, luego modernista y la definición madura en Óscar Wilde que hizo del personaje bíblico, en expresión de Edward Morgan Forster, un personaje redondo con entidad y propósito.

En los evangelios sinópticos Salomé es la hija de Herodías que embelesa a Herodes Antipas, hermano de su difunto padre Filipo y ahora padrastro, con una danza a cambio de la cual pidió la cabeza del Bautista que se hallaba encarcelado por él por denunciar la bigamia de Herodías. En Mateo 14: 1-12 Salomé pedía la cabeza del Bautista inducida por su madre. En Marcos 6: 14-29 se ofrecían detalles de esa persuasión. En su aniversario Herodes juró a Salomé ante representantes romanos ofrecerle lo que quisiese a cambio de su danza y ésta, previa consulta materna, demandó la cabeza de Juan el Bautista en una bandeja de plata. Obligado por su palabra el rey se la concedió por respeto a sus invitados. Salomé la entrega a su madre y los discípulos de Juan honraron el resto de su cuerpo con un monumento. En Lucas 9, 7-9, Herodes admitía haber degollado a Juan.

En la Biblia es una princesa sin nombre ni descripción de aspecto que ejecuta una danza de carácter desconocido que su madre usa para vengarse. Es Flavio Josefo en Antigüedades Judías de (93-4 ac) quien la nombra Salomé por derivación de salom o paz en hebreo. Cicerón, Plutarco y Séneca también la mencionan.

\section{Orígenes de un mito y primeras representaciones artísticas}

\section{Salomé en ciclos iconográficos primitivos}

Hay representaciones plásticas desde el siglo VI bien en ciclo iconográfico propio o ligado al Bautista. La medievalista Mónica Walker Vadillo señaló su representación marginal en tímpanos y capiteles (catedrales de Rouen, Tudela, Colegiata de Sta. María la Mayor de Alquézar en Huesca), bronces (Donatello), vidrieras de San Juan de Lyon, manuscritos (Evangelios de Liuthar en Aquisgrán, Salterio dorado de Munich) y pintura mural (Giotto en la capilla Peruzzi de Florencia). Del Renacimiento al siglo XIX contabilizó más de tres mil obras. Las representaciones medievales coinciden con la condena de Ambrosio de Milán, Agustín de Hipona y Juan Crisóstomo que 
indican la introducción del demonio en la danza de Salomé. La tradición occidental la representa con brazos de jarra en el norte y cuerpo de acróbata arqueado en el sur; la Oriental en Bizancio y Mediterráneo con el plato y la cabeza del bautista sobre su cabeza y la italiana guiada por demonios. Aumentan los ejemplos a partir del siglo XVI destacando Lucas Cranach el Viejo, Jacob Cornelisz y Bernardino Luini (Walker, 2016: 89).

\section{Salomé literaria, desarrollo de Herodías y trasvase hacia Salomé hasta la síntesis de Wilde}

Salomé fue una anécdota en Gregorio VIII, Aurelio Prudencio, el Góspel de Héliand o la Leyenda dorada. Pero es el texto latino Ysengrimus (1148) del monje Nivardus de Gante, hallado por Jacob Grimm en 1814 en la Biblioteca Nacional de Francia e incluido en el capítulo 13 de su Mitología Alemana (1835) el punto de partida de este mito cultural. Nivardus construyó la historia de amor con el beso de la cabeza decapitada. La cola cortada a Ysengrimus prefigura la decapitación (Ogane, 2011: 151-3). Nirvadus fusionó en Herodías a Frau Hulda, Fru Helle, Fru Helde, la antigua diosa germánica de la tempestad y su patrona Santa Verelda (Pharaildis en latín). De Grimm pasó a Heinrich Heine en Atta Troll. Ein Sommernachtstraum (1847) que veía en ella una esposa desaprovechada (Navarro, 2010; 135). Herodías era un espectro que sale de cacería con Diana y el hada Abunde la noche de San Juan y una Salomé errante trataba en vano de besar la cabeza del Bautista (Domínguez, 2017: 91) Heine inspiró a su vez a Mallarmé.

Wilde va a aprovechar esa potencia cruel propia de femme fatale debida al binomio eros-thánatos atribuida a las diosas lunares ya presente, como señalan Ogane y Domínguez, en Die Braut von Corinth de Goethe (1798), la Belle Dame sans Merci (1819) de John Keats y La Mort Amoureuse (1836) de Théophile Gautier.

Oscar Wilde recoge esa carga semántica de diosa lunar de Mallarmé de forma indirecta. Fue a través de la influencia de la Hérodias (1862) de Mallarmé en la Salomé (1867) de Joseph Converse Heywood. Eso redundó en el protagonismo de la propia Salomé y el motivo del beso de la cabeza muerta del Bautista. Y lo enlazó con la virginidad narcisista de ésta (Dominguez, 2017: 106-113). 
La importancia de la danza se encontraba en Yeats, el Eugene Sue de Le juif errant (1845) o Images of Good and Evil (1899) del poeta galés Arthur Symons. Esa danza se alinea con el deseo escapista del Romanticismo (l'ennui, die Sehensucht) que Moreau cristalizó en dos principios que evitaban la infiltración de lo literario en la pintura: el Principio de la bella Inercia (común a profetas, sibilas y alegorías de tumbas de Miguel Angel) y el Principio de la Riqueza necesaria que convertía el cuerpo de Salomé en una mujer-joya.

Son la pintura de Moreau y la escritura de Flaubert las que logran una descripción eficaz. En 1876 Gustave Moreau reapareció en el Salón de Bellas Artes con Salomé bailando ante Herodías tomando la idea de arqueología emocional de Rembrandt como fondo sobre el que avanza Salomé con la flor de loto (emblema femenino de virginidad y fecundidad) en gesto similar al pater familias del Juramento de los Horacios (1784) de Jacques-Louis David (Coocke, 2016). Su cuerpo seguía la ley de frontalidad egipcia y la hacía vértice de todas las miradas. Moreau impuso la mujer-joya carnal, tatuada de henna de terrible mirada. Joris-Karl Huysmans elogió en el capítulo V de $\grave{A}$ Rebours (1884) la obra de Moreau, su realismo "óptico" y comprensión como la deidad de la Lujuria o la Histeria, una belleza maldita dotada de catalepsia. (Huysmans, 1984: 177-183).

Gustave Flaubert proporcionó en Herodías (Tres cuentos, 1877) el contexto histórico, la caracterización de personajes y la descripción de la danza. El cruce de piernas en tijera o contrapposto de Moreau se convertía en la coreografía voluptuosa de una mariposa, Psique y un espíritu flotante en una danza del vientre acompañada de campanillas indias y flautas fenicias, con pantalón de velo negro bordado de mandrágoras plateadas y zapatillas con pluma de colibrí. Esa danza era estrategia de poder para Herodías, expresión de la belleza satánica con sinestesia (pintura, sonido y perfume) y ambigüedad de sexos y roles pues Salomé blande la flor de loto como un lirio (símbolo masculino) ante el voyeur, padre fálico Herodes (Salvador, 2005: 618-9). Gustave Flaubert es, a criterio de Charles Bernheimer, Elizabeth Grosz y Amanda Fernbach, el primero en connotar en Salomé un fetichismo reproductivo. Herodías adopta el rojo de la diosa maternal Cibeles y facilita la penetración ocular de los asistentes al ver a Salomé go pink (mostrando al doblarse el rosa vaginal) (Devereux, 2017: 126). 
Los ecos por repetición estaban en La Princesse Maleine (1889) de Maeterlinck o la estructura retórica del Cantar de los Cantares. De Ernest Renan en La Vie de Jesus (1869) tomó la visión poética de Cristo (Ballesteros, 2014:75).

Otra de las fuentes de Wilde, Moralités legendaires (1887) de Jules Laforgue permite un tratamiento mitocrítico desde la parodia por colusión con la ironía, la condensación y expansión del texto por la inclusión del yo narrativo como diferidor del texto y por la reutilización didáctica de fórmulas (Rodríguez, 1994: 93-97). Laforgue recoge la historia previa entre Salomé y el Bautista, la muerte de Salomé y la importancia de luna.

Wilde consolidó entonces el simbolismo de la luna, la sangre, el deseo, el decadentismo del arte por el arte y el orientalismo de los mantras (Lapeña, 2014: 175, 177). Insistió en la centralidad de la mirada. Mirar es ominoso (a la luna, como Acteón a Diana o Semele), o a Medusa, significa ser destruido (Ballesteros, 2014: 81).

\section{La Salomé de Wilde}

La Salomé (1891) de Wilde tropezó con leyes antiguas británicas y prusianas que prohíben la representación de personajes bíblicos. Se estrenó en París en el Théatre de L'Oeuvre en 1896 gracias a Aurélien Lugné-Poë. En Wilde Salomé deja de ser instrumento, venga una ofensa propia y construye una mujer fatal de enérgica capacidad de destrucción masculina con la perversidad añadida del beso necrofílico a su trofeo, la cabeza del Bautista (Rodríguez, 1996: 411). El beso que la Salomé virgen y despechada se cobra del Bautista se eleva en el imaginario e incentiva las producciones simbolistas. A partir de 1850 se dispara la iconografía artística de Salomé en Henri Regnault, Max Slevogt, Édouard Toudouze, Hugo von Habermann, Otto Friedrich, George Fréderic Watts. Después de Wilde aumentará desde las ilustraciones de Aubrey Beardsley a Max Klinger, Wilhelm Trubner, Lovis Corinth (1899), Edward Burne-Jones y Lucien Lévy-Dhurmer (1896), Pierre Bonnaud, Franz Von Stuck (1906), Leopold Schmutzler, George Olivier Desvalieres, Gustav Klimt (1909), Max Oppenheimer, Hans Unger, Francesc Masriera, Beltran Masses, Francis Picabia y muchos otros.

Donde Dorian Gray era objeto de deseo, Salomé era una persona con energías que si no se desarrollan tienen potencial destructivo. Salomé 


\section{Meléndez Táboas - Salomé en el cine}

rechazaba ser el fetiche de Herodes que ansía su boca, diente, sus pies de paloma, en definitiva, lo que Elliot L. Gilbert llamó la taxonomía del solipsismo. Su deseo incontrolable y sin supervisión termina consumiéndola y provocando su muerte (Walkowich, 2004: 93-99).

Después de Wilde Jean Lorrain empleó a Salomé como puente para sublimar la mujer como obra de arte, en Monsieur de Bougrelon (1897) y Monsieur de Phocas (1910) bajo los rasgos de Izé Kranile, la nueva bailarina de Folies Bergères. Salomé contribuye a construir una mujer moderna, flor venérea, azul y verde, cortesana pelirroja que accedía a la ósmosis amorosa por decapitación. Lorrain tomó de Las tres novias de Jan Toorop lo andrógino que inspiraba la mujer mítica sublimada, ambos images-repoussoir sobre las que volcar un ideal (Ferrety, 2015).

\section{Repercusión en letras iberoamericanas}

Rubén Darío en La muerte de Salomé (1891) empleaba el collar en forma de serpiente que se muerde la cola para significar eternidad, ambivalencia sexual y auto decapitación cuando cobra vida y la estrangula. Luego está el fetichismo de los cabellos de matiz animalizado (la leonada melena); los velos con los que Wilde alude al "desvelamiento sexual", la isotopía del fuego (luz bermeja, antorchas, incendio), la seducción por la danza y el sadomasoquismo o algolagnia. Delmira Agustini empleó esa asociación mujer-serpiente en Serpentina junto a la mirada fatal, cuerpo enjoyado y muerte o trascendencia por unión con el amado (Sánchez, 2016: 629).

Entre 1891 y 1918, tras su presencia marginal en Lope de Vega y Calderón, la literatura hispánica registró tres etapas de abordaje de este mito. La primera de 1891 a 1918 de construcción del arquetipo donde Rubén Darío y Emilio Carrère imaginan para ella una muerte por decapitación. Otra etapa de abandono progresivo del mito hasta 1936 con la interpretación misógina de Ortega y Gasset y la caricatura esperpéntica de Valle Inclán. Y una tercera etapa de reescritura desde la Salomé de Lourdes Ortiz en Los Motivos de Circe (1988) (Rodríguez, 1996-7). La cabeza del Bautista (1924) de Valle es la más estudiada pues la había incluido en la Sonata de verano de 1903 y la retomó por arte de segundo grado (Amado Alonso), intertextualidad (Melchor Fernández Almagro) o caricatura degradadora de Wilde (Guillermo Díaz Plaja). Descompuso sus unidades elementales para reorganizarlas por 
refracción como hacía el divisionista Seurat convirtiendo la princesa oriental en princesa criolla dentro de la "simetría viejo-niña" de la Tristana de Galdós (González, 1996: 251).

Valle mira a Goya y el gran guiñol desde su estética del esperpento. Aparece así lo macabro, el tema de la muerte y la doncella (Aszyk, 2012). Le atrajo de Wilde el uso de los actantes supermarionetas propuestos por Gordon Craig (Bonilla, 2003: 164). Heredó de él la mitología de la luna que continuaron el Romance de la luna, luna de Federico García Lorca y el madrigal dramático Ardiente-y-fría de Rafael Alberti (Navarro, 2010: 140). La mirada esencial al rito alucinatorio que fuerza a Herodes a cumplir su promesa fue clave a imitar de los filmes de Theda Bara y Alla Nazimova. (Bonilla, 2003: 166, 170).

\section{Salomé en el siglo XX: Weibermacht potencial intuido en la escena}

La Salomé cinematográfica es directamente deudora de la teatral y operística. Las mujeres de la escena identificaron el potencial como Weibermacht o género artístico de exaltación de su poder abierto por la obra de Wilde. E intentaron explotarlo para su exaltación personal (Ballesteros, 2015: 5).

En Alemania, tras levantarse la ley prusiana se realizaron 111 representaciones entre las que destacaron las producciones de Max Reinhardt con las actrices Gertrude Eysoldt y Tilla Durieux. El crítico Rainer Kohlmayer vio en Salomé la combinación del problema de la sexualidad fin de siglo y la Nueva Mujer. Salomé se percibía animalizada, mujer y tigre, paradigma de lo enfermizo, la homosexualidad, el judaísmo y la histeria. Salomé es perversa porque persiste en su deseo por el Bautista. Burckhard alabó en Wilde el astuto intercambio de la venganza materna por la pasión de la hija. Ernst Heilborn resaltó la progresión genérica en Wilde de la épica a la balada y el cuento de hadas que resuelve por ensalmo sin explicar el contexto histórico (Eugene, 2001: 152-163).

En 1905 Richard Strauss consagraba su popularidad con la adaptación operística de la que era precedente Erodes (1825) de Mercadante y a la que sucedería la de Florent Schmitt en 1907 y Antoine Mariotte en 1908 y $\mathrm{La}$ danza di Salomé (1952) de R. Lupi (Lapeña: 2014: 177).

Las mujeres de la bélle époque se apropiaron del personaje creado por la mirada escópica androcéntrica en términos de Laura Mulvey (Ruiz, 2013: 
3). Empresarias, coreógrafas, guionistas, bailarinas, diseñadoras y actrices quisieron añadirla a su repertorio. Entre ellas Sarah Bernhardt, intérprete ansiada por Wilde, Loïe Fuller (Serpentine Dance); La Bella Otero (1901), Blanche Walsh (1902), Gertrud Eysoldt y Tilla Durieux en la cia de Max Reinhardt (1903), Adorée Vilany en sus Spoken Dances (1905), Ruth St Dennis (1906), Mata Hari (1906), Mademoiselle Dazié (1907), Ida Rubinstein (1908) Carmen Tórtola Valencia (1908), Edith Lambelle Lagerfeld conocida como La Sylpheen The Remorse of Salome (1908), Miss Lotta Faust (1908), Mary Garden (1908,1913), Gertrude Hoffman (1910), Thamara de Svirsky (1910) y Alisa Koonen (1917) con escenografía de Alexandra Exter (Trav S.D., 2017).

La balletómana Carmen Tórtola Valencia apreciada por Carmen de Burgos y la Condesa de Pardo Bazán "personificó el Oriente, la seducción perversa de la mujer que ondula" en su montaje mejicano de 1918 con música de Strauss (Cavia, 2001: 34-35).

Y sobre todas ellas Maud Allan, la bailarina canadiense que en 1906 estrenaba Vision of Salomé en Viena que representó 250 veces en el Palace Theater of Varieties londinense en 1908 ganándose el apelativo The Salomé dancer. Estaba respaldada por sus conocimientos de estética modernista, simbolismo, fotografía e iluminación escénica adquiridos en 1895 en Berlín, la danza descalza de Duncan, las poses grecolatinas y la técnica de François Delsarte. Tuvo el apoyo de Margot Asquith, mujer del Primer Ministro Liberal y árbitro del gusto. Ella misma diseñaba sus trajes que remataba con perlas sus formas. Allan expresaba interioridad emocional, estados de consciencia transitorios y autoerotismo. En el ataque a su carrera por la ejecución de su hermano Theodore convicto de asesinato y la acusación de lesbianismo en titulares como El culto del clítoris las historiadoras feministas vieron un golpe ejemplarizante a mujeres fuera de norma. Allan extendió los límites entre virtud y vicio femeninos y el acceso a la propia mirada erótica (Walkowitz, 2003: 340-5).

Se creó así lo que Lawrence Kramer llama complejo Salomé: un cóctel de degeneración, decadencia, perversión sexual, antisemitismo, narcisismo, exotismo y femme fatale (Caddy, 2016: 164). 


\section{Salomé en el cine}

El cine habría de ocuparse de Salomé desde la filmación de Fuller por los Lumière. La primera película conocida es alemana, Tanzder Salome (La danza de Salomé, 1906), del director Oskar Messter y la bailarina Adorée Villany (Ruiz, 2013: 5).

Lapeña ha contabilizado unas setenta películas sobre Wilde o grabaciones de ópera de Strauss, una veintena de las cuáles son adaptaciones fieles de Wilde para televisión.

En la cinematografía italiana destacan las dos Salomé de Ugo Falena con Vittoria Lepanto (1910) y Nazia Napierkowska (La figlia d'Erodiade, 1916). En la cinematografía francesa $L$ 'inconsciente Salomé (Louis Feuillade, 1908) y en la británica los dos musicales de Warwick Cinemaphone Films en 1909 (Oh Salomé Oh, Oh, Oh y The Salomé dance Music). En Norteamérica son relevantes la Salomé or The Dance of the Seven Veils (J. Stuart Blackton, 1908) con Florence Lawrence, la Salome de Theda bara (J. Gordon Edwards, 1918), y Salomé de Charles Bryant 1923 de estética queer como expresión de deseos normativizados (Suárez, J.A., 2002 citado en Lapeña, 2014: 180)

Entre estas primeras Salomés de cine están Florence Lawrence, Gertrude Hoffmann, Lotta Faust, Olive Ann Alcorn, Eva Tanguay, la bailarina de la ópera Yvonne Daunt, Julane Johnston, Aida Overton Walker, Greta Nissen o Vilma Banky (Kendall, 1984: 73-90). Destacó entre ellas la francesa de origen polaco Stacia Napierkowska que comenzó su carrera en el vodevil del Folies-Bergères e interpretaría el papel de Salomé en tres filmes de 1908, 1916 y 1926 dirigidos por Albert Capellani, Ugo Falena y Fred LeroyGrandville respectivamente. La solidez de su actuación que inspiró a los cineastas futuristas se basaba en la formación balletística que revelaban determinadas posiciones y saltos (Catanese, 2018: 98-9).

\section{Salomé en el cine dependiente de Wilde}

En las artes cinematográficas la dependencia del texto de Wilde ha sido predominante yendo de la anécdota, a la adopción estética, la écfrasis actualizada del texto y su explotación metaficcional.

La Salomé (1910) de Ugo Falena con Vittoria Lepanto, luego notoria tras Lucrezia Borgia, se condensa entre el rechazo del Bautista a Salomé y la venganza de ésta en tres sets de decorado. Su actuación de femme fatal es ante 


\section{Meléndez Táboas - Salomé en el cine}

el banquete estructurado como tableau vivant donde Herodes y Herodías tienen los ropajes coloreados de rojo. Los movimientos de madre e hija se espejan en los sucesivos rechazos a las ofertas del tetrarca hasta la señal del brazo extendido con la que anuncia su intención de bailar. Lepanto recorre posiciones más o menos dancísticas y tras un giro derviche final disfruta de su trofeo eludiendo la muerte.

La Salomé (1918) de J. Gordon Edwards con Theda Bara trataba de capitalizar el éxito obtenido con Cleopatra y es uno de los títulos perdidos por combustión del celuloide. Las fotos conservadas muestran una femme fatal remozada en "vamp", categoría acreditada a Bara tras A fool there was (1915). El atuendo oriental de esta sex-symbol pionera motivó las protestas de varias iglesias en St. Louis (Missouri) y la prohibición de su visionado por niños (Embla, 2014). En dos ocasiones, en el desierto desde su palanquín y en el calabozo, Salomé trató de seducir al profeta y consumaba su victoria con el gélido beso a su cabeza muerta antes de que Herodes ordene su propia muerte. (Mary, 2015).

En 1923, el británico Charles Bryant se sirvió del encuadre, montaje, fondos encadenados y sobreimpresiones para crear un producto heredero de las reveries en la Salomé de su entonces esposa (Grünberg, 2011) Alla Nazimova quiso representarla dirigida por Orlenev en el Bowery Theatre neoyorkino dentro de su gira de 1906. La obra fue censurada en Rusia hasta el montaje en 1917 de Alexander Tairov. Peter M. Winters siguió fielmente el texto del autor irlandés que incluía la erradicación de la maldad de las mujeres matrilineal, que Herodes ve en Salomé por herencia de Herodías. La sangre del suicidio del príncipe Narraboth de Siria enamorado de Salomé ejerce de augurio fatal. Nazimova y Natacha Rambova unieron lo teatral y lo cinematográfico, pantomima y danza con influencias de Beardsley, Klimt y Moreau en el vestuario (Ruiz, 2013: 6). En los figurines Natacha Rambova se sitúa entre los artistas influidos por Aubrey Beardsley como Georges Barbier, Manuel Bujados o John Vassos. Nazimova rechazó unos primeros diseños de Rambova por un estilo que destacaba su figura sin curvas (Freedman, 2013: 107). Destacaba así la diferencia entre Herodías y el erotismo flapper de Salomé y se desviaba la capacidad de seducción a la mirada. Ninguna didascalia de Wilde describía el baile ni prescribía una Salomé de volúmenes rotundos. Tan solo perfumes, siete velos y que le retiren las sandalias (Morales, 2014: 81). 
En 1972 Carmelo Bene dirigió una Salomé, influida por la moda y el op art, que entendía como una partitura en celuloide donde cada personaje es un sonido. Bene como Herodes, sigue los diálogos de Wilde, elimina la danza y el fetiche de la cabeza decapitada. Los protagonistas aparecen desdoblados en personajes de una obra anterior de Wilde, La Sainte Courtisane (1894). Así Herodes en Onorio que se comunica con Salomé a través del espejo. Las uvas, vino y muerte desollado le emparenta con Dionisos. Salomé (Donyale Luna) está desdoblada en Myrrhina (Verushka). Carmelo Bene realizó dos adaptaciones teatrales anteriores y en ésta pretendió irritar deliberadamente con 4.500 encuadres que suponen las teselas de un banquete de péplum con gobernante infantil y caprichoso, los temas del doble y el precio de satisfacer el deseo (Lapeña, 2014: 183-188). Las nuevas femme fatales son las modelos Veruschka von Lehndorff descubierta en Italia e impulsada gracias a Blow up de Antonioni (1966) y Donyale Luna, activa participante de los swinging sixties londinenses y que acentúa con el cráneo rasurado el parecido que Dalí le había atribuido a Nefertiti. Hay en esta versión un abundante empleo del cuerpo desnudo y del cuerpo-joya. La Última cena se confunde con una bacanal y Jesucristo aparece como vampiro que opta por crucificarse a sí mismo. Salomé, imponiendo su cuerpo sobre un postrado Herodes le ciega en un desierto metafísico con los velos de colores que son metonimia de su danza.

\section{Filmes más allá de la cuarta pared con o sin Wilde}

En 1988 Ken Russell en The last dance, combina cine y montaje teatral de una representación privada para el propio Óscar Wilde (Nicholas Grace). Imagina su estreno londinense futurible con una pantomima en un burdel de lujo y el arresto policial posterior. Convierte a los verdugos en guardianas sádicas y duplica a Salomé (Imogen Millais) en la figura de un efebo al final de la danza de los velos que pretende ser una indemnización póstuma por la persecución a Wilde por su homosexualidad, pero en esencia mantiene el texto y su mensaje. La escena azulada, el contracampo anaranjado, el recurso barroco de la obra-dentro-de-la-obra, una mise en abîme, lo lleva a su terreno visual excesivo (Van Eecke, 2012: 5).

En Wilde Salomé (2011) su director, Al Pacino, encarna a Herodes y a un director que sería la reencarnación del propio Wilde a mayor gloria de su Sara Bernhardt (en este caso Jessica Chastain). Recupera la tradición de strip tease de los espectáculos teatrales y de vodevil de la primera década del siglo 


\section{Meléndez Táboas - Salomé en el cine}

XX. Dedica mucha atención a la pasión por Iokanáam que motiva el paso de la virginidad adolescente a la sexualidad en la princesa, así como la ofensa a su dignidad y orgullo y la necrofilia de ese beso final. Sin embargo, la Salomé de estas versiones fieles a Wilde, sea Alla Nazimova, Imogen Millais-Scott o Jessica Chastain nos devuelven la imagen de princesas infantiles carentes de tolerancia a la frustración de sus deseos.

\section{Otras Salomés posibles a partir de Wilde}

En este último apartado consignamos otro grupo de filmes que aprovechan sólo ciertos elementos del texto de Wilde o se apartan de él de forma decidida. Son películas al servicio de intereses distintos.

\section{Salomé como ilustración bíblica}

En la película Salomé (1953) dirigida por William Dieterle ésta es una princesa de Galilea criada en Roma que desea casarse con Marcelo, sobrino de Tiberio. Éste, contrario al enlace, la expulsa de Roma. La envía en una galera con Poncio Pilato y el comandante Claudio (Stewart Granger) que durante el lustro de servicio en Galilea abrazó el cristianismo y va a proteger al Bautista. Salomé está agradecida por haber crecido en Roma libre de la lujuria de su padrastro Herodes (Charles Laughton) y preocupada por la lapidación de su madre Herodías (Judith Anderson) por las acusaciones de Bautista. Herodes teme matarle y Herodías fuerza la gratitud de su hija con un baile que equivale a convertirla en concubina. Salomé aparece atrapada, influida por la fe de Claudio danza pensando que salvará al Bautista para descubrir horrorizada que la usaron para precipitar su muerte. La cristianización de la trama, en línea con Quo Vadis (1951) de Melvin Leroy, es el rasgo distintivo de esta versión. King of Kings (1961) de Nicholas Ray enfatiza el trono desde el que Salomé (Brigid Bazlen) realiza su petición y la gran jaula de pájaros del salón real, símbolo del cautiverio del que la danza de velos es fuga. 


\section{Salomé migrante}

El mito de Salomé y la Salomanía fue aprovechada en la escena y el cine por intérpretes que pertenecían a minorías migrantes y, en ocasiones, también a comunidades judías asentadas en Estados Unidos.

La suspensión de la Salomé de Strauss en el Metropolitan en 1907 motivó a la bailarina Bianca Froelich para llevar la Danza de los 7 velos al Lincoln Square Variety Theater. Varios empresarios compitieron por el número y en octubre de 1908 había 24 espectáculos de Salomé. El director del Teatro Victoria, Willie Hammerstein, envió a Gertrude Hoffman a Londres a estudiar a Maud Allan para montar el suyo. Florence Ziegfield añadió una parodia a sus Follies en 1907. La actriz Fanny Brice (inmigrante húngara llamada Fania Borach) aceptó interpretar el rol de Salomé con la canción Sadie Salomé: go Home que le brindó Irving Berling para dar el salto a las Ziegfield Follies (1908). Pero fue Mademoiselle Dazie (antes conocida como La Belle Dazie, Daisy Peterkin y Le Domino Rouge) quien incendió en las Follies la Salomanía rematando su Jiu-jitsu Waltz con un número de Salomé tan popular que le permitió abrir una escuela que graduaba cada mes ciento cincuenta alumnas que inundaron Norteamérica de especialistas en strip tease.

Hubo pronto una identificación entre Salomé y la mujer judía, por la relevancia de Sarah Bernardt e Ida Rubinstein convertida en icono estético decadente apoyada por el dinero de Sir Walter Guiness y los retratos de Romaine Brooks. Fue Gustave Moreau quien asoció a Salomé a una nueva representación del cuerpo judío erotizado extraído de su estudio en Venecia de Bellini, Giorgione y la pintura bizantina. Ese cuerpo pervivía en la artista lesbiana de origen judío Lucy Schwob, sobrina del corrector de francés de la Salomé de Wilde Marcel Schwob y conocida como Claude Cahun. (Freedman, 2013: 96-7).

La judía polaca, Anzia Yezierska, escribió en 1922 la novela adaptada al cine con título homónimo Salome of the tenements (Sidney Olcott, 1925). En ella la heroína de esas corralas, Sonya Vrunsky (interpretada por Jetta Goudal), responde al tipo que Pam Morris llama 'la tentadora'. Se basa en las propias experiencias de la escritora criada en settlements reformistas que cambia la carrera de Ciencias domésticas por Magisterio tras falsificar el título de secundaria y donde asiste desde 1918 a seminarios de Dorothy 


\section{Meléndez Táboas - Salomé en el cine}

Scarborough y el reformador John Dewey que le anima a escribir (Vargas, 1998: 11, 228).

Vrunsky capitaliza su etnicidad exótica, el Oriental mystique mezcla de paganismo, inconsciencia, histeria y marginalidad asociada a la danza, actividad liberadora del destino de cuidadora nutricia. Yezierska utilizó los credos americanos de individualismo, autoconfianza y persecución agresiva de un destino feliz que feminiza para romper barreras sociales como Nueva Mujer americana. La heroína transforma su aspecto gracias a la moda. Yezierska se inspira en su amiga Rose Pastor que se casó con el millonario filantrópico J.G. Phelps Stokes y en su propio amor platónico por John Dewey. Influyen también el cine de Griffith y Eisenstein y las películas realizadas para el guetto judío de narrativa linear y también elíptica como The Jew's Christmas y The romance of a Jewess que continuaban las representaciones de Bessie Tomashevsky en el Yiddish theater en 1908 (Coklin, 2006: 138-140).

\section{Salomé ménade}

Salomé comparte con otras femme fatale la danza como arma de seducción sea en la Carmen de Pola Negri (Ernst Lubitsch, 1918), la Salomé de Wilde, Lulú de Wedekind o Conchita de La mujer y el pelele de Pierre Louÿs (Poyato, 2006: 163).

El elemento central a Salomé era esa danza de catarsis, dionisíaca, que hacía de ella una bacante o ménade. Es la acción principal que lleva a cabo como poder primitivo, ser neurótico finisecular que oficia de chivo expiatorio o individuo-síntoma en expresión del psiquiatra Eric Daviller que preserva la idea de normalidad del grupo. Danza que admite análisis aplicando las fases de la histeria del modelo de Jean-Martin Charcot: epiléptica, danza de los velos de movimientos largos y alucinatoria con actitudes pasionales y delirio tras la satisfacción del beso (Gomes, 1997: 62, 65). La danza forma parte de su poder como princesa, le permite adoptar la "soberanía performativa" en terminología de Judith Butler. Esa imposición casi mágica de la autoridad busca la "Implantación", en expresión de Michel Foucault, que fuerza por el discurso un cambio psicológico en otro. Con su lenguaje de la Danza de los Siete Velos logra comunicar la perversidad de sus deseos (Kramer, 2014: 103, $105,108)$. 
En la Salomé (1973) que el escritor Clive Barker adapta de Wilde para televisión lo más llamativo aparte de la experimentación en fotografía, sonorización e iluminación es la danza vengativa rodada en cámara lenta y posterizada que sigue al intento de estrangulamiento por el Bautista.

Pero es la danza filmada en la Salomé (2002) de Carlos Saura (2002) el título que hizo de ella el elemento central. La primera media hora se sirve del formato documental y entrevista. Pere Arquillué como trasunto del director proporciona en off los datos bíblicos, la premisa del film sobre la pasión amorosa y la venganza como sinrazón de toda la tragedia. Nos muestra la inspiración en Julio Romero de Torres, las decisiones escenográficas con iluminación binaria solar (amarilla) y lunar (azul). Inserta fragmentos de entrevistas a Aida Gómez (Salomé), Paco Mora (Herodes) y Javier Toca (Bautista), conversaciones con el compositor Roque Bolaños y el figurinista Pedro Moreno. El resto describe sin palabras la lucha entre lo carnal y espiritual que lleva a la destrucción del ser amado. Aquí Bautista parece tentado a ceder ante la corporalidad de Salomé hasta la irrupción de la llamada espiritual. Herodías fuerza la entrega de Salomé a Herodes y es Salomé la que horrorizada tras la muerte que la satisfacción de su propio deseo ha provocado se amortaja.

\section{Salomé como agente de cambio para el bien}

El potencial trasgresor y de desplazamiento de poder hacia la mujer de Salomé lo había advertido José Ortega y Gasset en 1921 en Esquema de Salomé por el intercambio en ella del instinto natural de entregarse femenino por el masculino de apoderarse convirtiéndola en una "Mujer de presa" (Ortega, 1969: 102-4). Las estudiosas de género Mary Ann Doane, Julie Grossman y Angela Martin vieron el potencial empoderador de la mujer fatal pero también su ambivalencia. Virginia Allen, Bram Djikstra y Elizabeth K. Menon, coincidieron en señalar en Salomé una fantasía proyectiva masculina de mantenimiento del control ante la independencia económica, política y sexual de la mujer (Jackson, 2015: 50, 52).

El origen del sesgo misógino estaba en Flavio Josefo y su fuente Nicolás de Damasco. Salomé había figurado en la Edad Media y el Renacimiento en un género literario y artístico llamado Weibermacht o Poder 


\section{Meléndez Táboas - Salomé en el cine}

de las Mujeres junto a Salomé, Dalila, Judith, Betsabé y Jael (Lassley, 2017: $10)$.

En la filmografía de Salomé es posible identificar ciertos títulos con un hipertexto más notorio que permiten plantear una Weibermacht cinematográfica que explotara el potencial de Salomé como imagen-signo empoderadora de la mujer que superase la cadena Mujer $=$ sexo $=$ pecado $=$ muerte prevalente en los siglos XV y XVI por una secuencia Mujer $=$ sexo $=$ deseo satisfecho $=$ poder. Una Salomé libre de la condena a muerte patriarca que pueda disfrutar de su propio deseo, del arte y cuya subjetividad autónoma no se vea como amenaza.

Para esa reapropiación es preciso deshacer la asociación decadente de la Nueva Mujer con aberración, inversión sexual, dedicación al conocimiento inútil, artificialidad, deshumanización híbrida, malditismo, histeria y transformación por el arte en objeto fálico sustitutivo (Escaja, 2008: 43).

Pueden rastrearse varios ejemplos que permiten superar la satanización de Salomé. En El Palacio de las Maravillas (The Show, 1927 de Tod Browning) se desarrolla un vodevil circense de la historia del Bautista. Salomé (Renée Adorée) y Bautista (John Gilbert) son antiguos enamorados, aunque ahora ella salga con el gánster El Griego y él tontee con la hija de un tratante de ovejas llamada Lena. Tras un desarrollo criminal él logra separar la Salomé actriz de la hija abnegada de un ciego y la revelación de su bondad le inspira a elegir la buena senda y una nueva feliz con ella.

La Salomé (1978) que Pedro Almodóvar realizó en 16 milímetros previo a su primer largometraje plantea el encuentro por unas colinas de Abraham (Fernando Hillbeck), Isaac (Agustín Almodóvar) y Salomé (Isabel Mestres). Mestres acababa de interpretar ese papel en Jesús de Nazareth (1977) de Franco Zeffirelli donde danzaba rodeada de antorchas y sostenía un duelo de miradas con Herodes (Christopher Plummer) que incluía planos detalle de que Almodóvar replicó. Se combina el sacrificio de Isaac con el del Bautista. Salomé accede a bailar con las trompetas, el pasodoble El Gato Montés y velos que entrega al viento emulando a Loïe Fuller y la Victoria de Samotracia. Tras la danza Dios comunica a Abraham que ha sido probado para recordarle que es humano y debe pecar. Recogerá los velos negros que servirán para que las mujeres respeten la misa. Salomé era una manifestación divina que orientaba al bien. 
En la versión que dirige Charles Lamont, Salome Where She danced, se produjo una reapropiación nacional de la historia a cargo de Michael J. Philips.

Si se aplica en ella el análisis propuesto por Eugenio Sulbarán Piñeiro (2000) que incluye diez puntos donde la identificación de secuencias, puntos de giro, caracterización, leyes de repetición, conflicto y premisa e interpretación son los principales podemos extraer del título que se aparta más de las premisas iniciales de Salomé una nueva vía de exploración del mito.

La protagonista es una bailarina austríaca llamada Anne-Marie (interpretada por la actriz originaria de Vancouver Yvonne de Carlo) que ejerce sucesivamente su poder de fascinación sobre Von Bohlen (Albert Dekker) la mano derecha del Conde Von Bismarck, que la persigue hasta América, un corresponsal de la guerra civil norteamericano convertido en espía llamado Jim (Rod Cameron), un jovencísimo oficial austríaco llamado Kurs que pierde la vida en la guerra franco-prusiana, un excombatiente confederado virginiano desencantado de Grant metido a bandido llamado Cleve Blunt (David Bruce) y un empresario ruso llamado Dimitrioff. Von Bohlen sería el equivalente de Herodes, Jim es quien propone que ella le seduzca primero a él y luego en el salvaje Oeste a todo el pueblo de Drinkman Wells donde la referencia del topónimo (well, pozo, sea de condenación o celda del bautista) no parece casual. En esta localidad pasará de la Venus surgiendo de la venera del teatro vienés a encarnar a Salomé con ayuda de Madame Europe (Marjorie Rambeau), una antigua cupletista antaño exitosa en cabarets germanos, suerte de Herodías sobrepasada por los encantos de la juventud. La Salomé de pantomima y vodevil es así superada por la cinematográfica. Asistimos por fin a una Salomé que combina sabiduría dancística con coreografía de baile del vientre que desafía al bandido reanudando su actuación con actitud concienzuda de profesional de la danza añadiendo el baile de la cobra y un giro en espiral derviche redondeando una completa sugestión oriental.

Las secuencias clave están a su vez seguidas de puntos de giro en el guión y son las interpretativas. Así la Venus balletística la convierte en espía y provoca su exilio norteamericano. La larga performance de Salomé, cuya coda final persigue la rendición del bandido Cleve provoca en inicio su secuestro y luego el comienzo de regeneración de este como su enamorado; una secuencia de canto acompañada de piano le reporta el apoyo del filántropo 
de las artes Dimitrioff que pone a su disposición un Rembrandt y un teatro en San Francisco. Allí la voluntad de cambio de Cleve parece flaquear y con ayuda del asistente chino de Dimitrioff Anne Marie le tiende una trampa para probar su afecto y reforzar su seducción por vía de una danza ritornello de nuevo exótica y asiática con atavíos tailandeses. Luego vemos que se cumplen en el filme la ley de progresión continua y la de repetición. El clímax final se produce antes de ese estreno en San Francisco donde Von Bohlen da caza a Anne Marie y muere tras un duelo de esgrima con Cleve que devuelve a este último a la vía criminal. Dimitrioff como deus- ex machina facilita el lastminute-rescue y el final feliz, dentro de la ley, de la pareja rumbo a Virginia.

En este título Salomé se reapropia del control de su cuerpo, voluntad, sexualidad y elección afectiva desvinculada de condena o pecado. Ejerce su poder de fascinación para el bien y, si bien paga el precio de la renuncia a la carrera artística en favor de su pasión amorosa (la renuncia al reino), nadie toma esa decisión por ella.

\section{Conclusión}

En Woman and the Demon: the Life of a Victorian Myth, Nina Auerbach (1982) señaló 4 tipos de mujer presentes en la literatura del XIX: 1) el ángel doméstico; 2) mujer con pasado (y dentro de ella la mujer fatal, New Woman, la mujer salvaje, la actriz); 3) La prostituta y 4) la nueva mujer presente en Thomas Hardy, Bram Stoker, Oscar Wilde, Henry James y en autoras como Mona Caird, Menie Muriel Dowie, Ella Hepworth Dixon, George Egerton, Netta Syrett, Evelyn Sharp, Olive Custance, Victoria Cross.

La irrupción de los tres últimos tipos se debía al paso de una economía de producción a una economía de consumo que suponía a su vez la transición de la sexualidad de reproducción a la sexualidad unida al placer. Esta última se percibió como energía invasiva, caos y amenaza de una sociedad feminizada por la que la Salomé de Wilde debía morir restaurando el orden patriarcal (Martínez, 2010: 4-7).

Después del recorrido expuesto sobre la construcción del mito cultural de Salomé se ha identificado en la Salomé de Wilde la doble responsabilidad de su vigencia y de su misoginia. Gran parte de los topoi simbolistas (crueldad, mujer-serpiente, perversidad, virginidad narcisista, histeria, binomio erosthánatos, la muerte y la doncella) deben desmontarse. 
Salomé debe retener con orgullo su medio de expresión artístico (la danza) y la formulación del cuerpo (sea cuerpo-joya, estetizado, animalizado y dotado de gracia que aúne belleza y movimiento). Puede preservar su poder lunar y la mirada con toda su carga de subjetividad. Debe estar en posesión de su deseo y voluntad realizando un ejercicio similar a Delmira Agustini desmontando la condición de fetiche fálico, usar la propia voz para transformar el eros y experimentar sin temores el éxtasis de su satisfacción (Escaja, 2008: 56-58).

El poder de fascinación de su danza, de la comunicación asertiva de la propia voluntad, de su deseo de ósmosis con otro sujeto de deseo, con el amado es un motivo que mantiene su fuerza. Como intuyeron las bailarinas exóticas y actrices de comienzos del cine y sus últimas intérpretes el mito mantiene un gran potencial como Weibermacht tanto para ellas como para sus audiencias.

\section{Referencias}

Aszyk, U. (2012). Intertextualidad y transformaciones transgresoras en el teatro de Valle-Inclán: «La cabeza del Bautista» ante el cuento evangélico y el mito de Salomé. Itinerarios: revista de estudios lingüísticos, literarios, históricos y antropológicos, 16, 13-28.

Ballesteros, A. (2014). Decadencia y perversión: Óscar Wilde y la creación victoriana del mito de Salomé. Herejía y belleza: Revista de estudios culturales sobre el movimiento gótico, 2, 69-87.

Ballesteros, R.M. (2015) Raras y olvidadas: directoras del cine mudo. Aposta, revista de Ciencias Sociales, 67, 1-25.

Bonilla, R. (2003). Salomé danza ante los tetrarcas modernistas: Valle-Inclán y Castelao. Plástica, caricatura y cine en un mito de Wilde. Analecta Malacitana, 26 (1), 159-179.

Caddy, D. (2016). Picturing the Paris Salome, May 1907. Opera Quarterly, 32(2/3), 160-191. doi: 10.1093/oq/kbx005.

Catanese, R. (2018). Futurist Cinema: Studies on Italian Avant-Garde Film. Amsterdam: Amsterdam University Press.

Cavia N, V. (2001) Tórtola Valencia y la renovación de la danza en España. Cairón: revista de ciencias de la danza, 7, 7-28. 
Coklin, L. (2006). Between the Orient and the ghetto: a modern immigrant woman in Anzia Yezierska's Salome of the Tenements. Frontiers - A Journal of Women's Studies, 27, 2,136-161. doi: 10.1353/fro.2007.0002

Cooke, P. (2016). In Mucri. Retrieved July 20, 2018 from http://mucri.univparis1.fr/salome/

Devereux, C. (2017). Salome, Herodias, and the «curious transition»: The Cultural Logic of Reproductive Fetishism in the Representation of Erotic Dance. English Studies in Canada, 43, 2/3, 121-147. doi: 10.1353/esc.2017.0020.

Domínguez, L. (2017). Frau Hulde - Herodías - Salomé: La construcción del mito en el canon literario europeo. In Arriaga, M. (ed.), Escritoras en torno al canon (pp. 87-119). Benilde.

Eugene, W. (2001). Oscar Wilde, Salome, and the German Press 1902-1905. English Literature in Transition, 1880-1920, 44 (2), 148-180.

Embla (2014). Theda Bara in Lost Film Salomé 1918. In Fromthebyone. $\begin{array}{llll}\text { Retrieved July } & 22, & 2018 & \text { from }\end{array}$ https://fromthebygone.wordpress.com/category/salome-2/

Escaja, T. (2008) Modernistas, feministas y decadentes. Nuevas aproximaciones a «Salomé decamitada»: el caso de Delmira Agustini. Cuadernos de Literatura, (13), 25, 37-60.

Ferrety, V. (2015). Salomé et la figure féminine chez Jean Lorrain. Çédille: Revista de Estudios Franceses, 11, 183-200.

Freedman, J. (2013). Transformations of a Jewish Princess: Salomé and the Remaking of the Jewish Female Body from Sarah Bernhardt to Betty Boop. Philological Quarterly. 92,1, 89-114.

Gomes, P. (1997). Alterity and identity: pale white, strange black, violent purple: dancing with Salome and Elektra. Cairon: revista de ciencias de la danza, 3, 59-72.

González, A. (1996). Valle-Inclán spectrographe: Salomé réfractée. Anuario de estudios filológicos, 19, 249-254.

Grünberg, T. (2011). Salomé, reine d'Angleterre: destins esthétiques de la Salomé d'Oscar Wilde (Aubrey Beardsley, Charles Bryant, Ken Russell). Cahiers victoriens et édouardiens, 73, 165-178. doi: 10.4000/cve.2193 Huysmans, J. K. (1984). A contrapelo. Madrid: Cátedra. 
Jackson, S. E. (2015). Embodied Femmes Fatales: Performing Judith and Salomé on the Modernist German Stage. Women in German Yearbook, 31, 48-72. doi: 10.5250/womgeryearbook.31.2015.0048

Kendall, E. (1984). Where She Danced: The birth of American Art-dance. Berkeley: University of California Press.

Kramer, L. (2014). Opera as Case History: Freud's Dora, Strauss's Salome, and the Perversity of Modern Life. The Opera Quarterly, 31, 1-2, 100115. doi: $10.1093 / \mathrm{oq} / \mathrm{kbu} 026$.

Lapeña, O. (2004). La imagen del mundo antiguo en la ópera y en el cine. Continuidad y divergencia. Veleia: Revista de prehistoria, historia antigua, arqueología y filología clásicas, 21, 201-218.

Lapeña, O. (2006). El ideal de la belleza y la nostalgia del pasado: Venus en el cine y la televisión. Iberia: Revista de la Antigüedad, 9, 167-190.

Lapeña, O. (2014). Salomé en el cine: el evangelio pop de Carmelo Bene. In Salvador Ventura, F.J. (Ed.), Cine y representación: re-producciones de mundos en re-construcciones fílmicas (pp. 173-192). Université ParisSud.

Lassley, J. (2017). Herodias, Salomé, and John the Baptist's Beheading: A Case Study of the Topos of the Heretical Woman. International Social Science Review, 93, 1, 1-15. Retrieved from: http://digitalcommons.northgeorgia.edu/issr/vol93/iss1/1

Markowich, H. (2004). The Princess,Persona, and Subjective Desire: A Reading of Oscar Wilde's Salome. Papers on Language \& Literature, 40, $1,88-101$.

Mary (2015). Lost filmes: Salomé (1918). In Weheartvintage Retrieved July 22, 2018 from http://weheartvintage.co/2015/06/25/lost-films-salome$1918 /$

Martínez, L.J. (2010). Decadentismo y misoginia: visiones míticas de la mujer en el Fin del Siglo. Kleos: estemporaneo di studi e testi sulla fortuna dell'antico, 19, 593-606.

Navarro Durán, R. (2010). Salomé o la tentación irresistible. Anagnórisis: Revista de investigación teatral, 1, 130-144.

Ogane, A. (2011). Parcours du mythe d'Hérodias: Ysengrimus, Atta Troll, Trois contes, Salomé. Romantisme, 154 (4), 149-160. doi: 10.3917/rom.154.0149 
Ortega y Gasset, J. (1969) Esquema de Salomé. En El Espectador. Vol IV (pp. 102-104), Salvat.

Poyato, P. (2006) De la Carmen de Merimé a la Conchita de Buñuel en Ese oscuro objeto del deseo. Annali Online de Ferrara. Lettere. Vol. 2, 158170.

Rodríguez, A. (1994). Laforgue, Güiraldes y el tema de Salomé. El Guiniguada, 4-5, 91-100.

Rodríguez, D.F. (1996-7). Del arquetipo a la reescritura: la trayectoria de Salomé en las literaturas hispánicas, Archivum: Revista de la Facultad de Filología, 46-7, 409-424.

Ruiz, B. (2013). Besaré tu boca, Iokanaán. Arte y experiencia cinematográfica en Salomé de Alla Nazimova. En Costa Valente, A. y Capucho, R. (coords.). Avanca / Cinema 2013. International Conference (pp. 86-100). Avanca.

Salvador, A. (2005). Salomé sensual: de la mirada de Moreau a la palabra de Casal. En Valcárcel, E. (ed.) La literatura hispanoamericana con los cinco sentidos (pp. 617-625). Universidade de Coruña.

Sánchez, A. (2016). Visiones míticas y desmitificación: la figura de Salome en el modernismo hispánico. Castilla: Estudios de Literatura, 7, 623-651.

Sulbarán, E. (2000). El análisis del film: entre la semiótica del relato y la narrativa fílmica. Opción: Revista de Ciencias Humanas y Sociales, 31, 44-71.

Tarab- Al Aldalus. (2013). La mitificada danza de Salomé. In TarabAlAndalus. Retrieved July 26, 2018 from https://tarabalandalus.blogspot.com/2013/06/la-mitificada-danza-desalome.html

Trav, S. D. (2017). Several Salomés and the history of dance of seven veils. In Travalanche. Retrieved July 27, 2018 from https://travsd.wordpress.com/2017/06/24/several-seminal-salomes-andthe-dance-of-the-seven-veils/

Van Eecke, C. (2012). Moonstruck Follies. Ken Russell's Salome's Last Dance (1988) as Baroque Performance. Image \& Narrative, 13, 2, 5-25. Retrieved from: http://www.imageandnarrative.be/index.php/imagenarrative/article/view/ 231 
Vargas, M. D. (1998). El sueño americano: una ilusión inalcanzable para la mujer judía inmigrante (Doctoral Dissertation) Availaible from Universidad de Malaga database. (Publication No. 11392149)

Walkowitz, J. R. (2003). The "Vision of Salome": Cosmolitanism and Erotic Dancing in Central London, 1908-1918. American Historical Review, 108 (2), 337-376. doi: 10.1086/533238.

Walker, Mónica A. (2016) Salomé. La joven que baila. Revista Digital de Iconografía Medieval, VIII, 15, 89-107.

Suárez, J. A. (2002). Homosexualidades en el primer cine de vanguardia norteamericano. Salomé, La caída de la casa Usher y Lot en Sodoma. Orientaciones, 3, 21-32.

Amelia Meléndez Táboas: Universidad Nebrija, Spain E-mail address: amelende@nebrija.es 